\title{
Effect of Bifidobacterium bifidum Fermented Milk on Helicobacter pylori and Serum Pepsinogen Levels in Humans
}

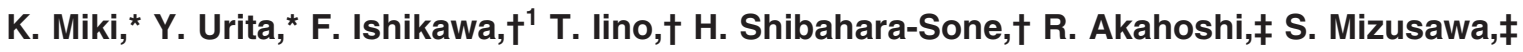 \\ A. Nose, $¥$ D. Nozaki, $¥$ K. Hirano, $¥$ C. Nonaka, $\ddagger$ and T. Yokokura† \\ *Faculty of Medicine, Toho University, Ota-ku,Tokyo 143-8540, Japan \\ †Yakult Central Institute for Microbiological Research, Kunitachi, Tokyo 186-8650, Japan \\ $\ddagger$ Faculty of Research and Development, Yakult Honsha, Shimbashi, Tokyo 105-8660, Japan
}

\begin{abstract}
Helicobacter pylori infection is an important risk factor for gastric diseases. Some probiotics are useful for suppressing $H$. pylori infection. Bifidobacterium bifidum YIT 4007 can improve the experimental gastric injury in rats and the disease stages on the gastric mucosa in peptic ulcer patients. We evaluated the fermented milk using a clone (BF-1) having the stronger ability to survive in the product than this parent strain to clarify the in vitro suppressive effect of BF-1 on $H$. pylori and the in vivo efficacy of BF-1 fermented milk on $H$. pylori and gastric health. In the mixed culture assay of BF-1 and H. pylori, the number of pathogens was decreased such that it was not detected after $48 \mathrm{~h}$ in the Brucella broth with a decrease in $\mathrm{pH}$ values. In the cell culture experiment with human gastric cells, the $H$. pylori infection-induced IL-8 secretion was suppressed by the preincubation of BF-1. In a human study of 12-wk ingestion (BF-1 group, $\mathrm{n}=40$; placebo group, $\mathrm{n}=39$ ) with a randomized double-blind placebo-control design, the H. pylori urease activity and gastric situation were evaluated using a urea breath test (UBT) and the serum pepsinogen (PG) levels as biomarkers for inflammation or atrophy, respectively. In the H. pyloripositive subjects, the difference ( $\triangle \mathrm{UBT}$ ) of the UBT value from the baseline value in the BF-1 group ( $\mathrm{n}=$ $34)$ was lower than that in the placebo group $(n=35)$ at 8 wk. The baseline UBT values showed a negative correlation with $\triangle \mathrm{UBT}$ values at 8 and $12 \mathrm{wk}$ in the BF-1 group but not in the placebo. In the PG-positive subjects classified by the PG test method, the BF-1 group was lower in $\triangle \mathrm{UBT}$ values than the placebo group at 8 and $12 \mathrm{wk}$. In the active gastritis class by PG levels, the BF-1 group was lower in their $\triangle \mathrm{UBT}$ values than the placebo at 8 and $12 \mathrm{wk}$. The PG I levels in the BF-1 group were lower than the placebo at 12
\end{abstract}

Received December 1, 2006.

Accepted February 1, 2007.

${ }^{1}$ Corresponding author: fumiyasu-ishikawa@yakult.co.jp wk. The PG II levels in the BF-1 group did not change during the ingestion period, but the placebo was increased. The PG I/II ratios slightly decreased from baseline at 12 and $20 \mathrm{wk}$ in the BF-1 and placebo groups. These patterns were also observed in the H. pyloripositive subjects. The improving rates of upper gastrointestinal symptomatic subjects and total symptom numbers in the BF-1 group were higher than those in the placebo. These results indicate that BF-1 fermented milk may affect $H$. pylori infection or its activity, gastric mucosal situation, and the emergence of upper gastrointestinal symptoms.

Key words: Bifidobacterium bifidum, Helicobacter pylori, pepsinogen, probiotics

\section{INTRODUCTION}

Helicobacter pylori causes inflammation of the gastric mucosa and the promotion of gastric acid secretion, and then persistent infection leads to chronic gastritis, atrophic gastritis, and peptic ulcer (Morris and Nicholson, 1987; Kawaguchi et al., 1996). Atrophic gastritis is closely related to gastric cancers (Uemura et al., 1997; Yoshihara et al., 1998). The $H$. pylori-infected subjects with atrophic gastritis are high-risk populations (Uemura et al., 2001). The grade of atrophy in the gastric mucosa, which is judged by the serum pepsinogen (PG) levels (Samloff et al., 1982; Miki et al., 1987, 1993, 2003), is related with the detection rate of gastric cancers by using endoscopy (Miki, 2001). These findings indicate that it is important to maintain the mucosa function and prevent gastric diseases to suppress the $H$. pylori infection and improve the gastric mucosa.

Antibiotics, such as amoxicillin, clarithromycin, or nitroimidazoles, are effective drugs against $H$. pyloriinfection, and triple or quadruple combination therapy using these antibiotics and acid-suppression drugs (proton pump inhibitors or $\mathrm{H}_{2}$-receptor antagonists) are performed for the eradication of $H$. pylori (Malfertheiner et al., 2002; Oderda, 2003). However, there are some failures in the eradication therapy by antibiotics (Lind 
et al., 1999; Mascitelli and Pezzetta, 2003), which have been indicated to be the adverse potential for the emergence of drug-resistant $H$. pylori strains (Matsumoto et al., 1997) and the occurrence of side effects, such as reflex esophagitis due to an increase in acid secretion (Hamada et al., 2000).

Probiotics are microorganisms exerting beneficial effects on their host's health by improving the intestinal flora balance (Fuller, 1991). The genera Lactobacillus and Bifidobacterium as candidates of probiotics, often used for fermented dairy products or food supplements, are expected to suppress deleterious bacteria in the gastrointestinal tract by changing the microbiological environment. The ingestion of probiotics contributes to the improvement of bacteria and viral infection, diarrhea due to antibiotics, inflammatory bowel disease, and irritable bowel syndrome (de Vrese and Schrezenmeir, 2002). Several reports describe that probiotics have the potential to inhibit $H$. pylori growth in vitro (Midolo et al., 1995; Coconnier et al., 1998), to improve mucosal inflammation in $H$. pylori-infected animals (Sgouras et al., 2004, 2005), and to suppress the secretion of IL-8, a potent proinflammatory cytokine, in the H. pylori-infected gastric cells (Sgouras et al., 2005; Tamura et al., 2006). Furthermore, some strains can decrease biomarker values for $H$. pylori in humans (Sakamoto et al., 2001; Cruchet et al., 2003; Pantoflickova et al., 2003; Linsalata et al., 2004). These findings indicate that selected probiotics may act on $H$. pylori in vivo.

Bifidobacteria preferably inhabits the colon and produces acetic acid as well as lactic acid under anaerobic conditions, contributing to the health of the lower gastrointestine. Therefore, the Bifidobacterium, unlike the Lactobacillus, has not been an intriguing probiotic against $H$. pylori in the stomach and the upper gastrointestinal tract. However, some reports showed the potential of Bifidobacterium to suppress $H$. pylori infection and to improve the gastric mucosa pathology. Nagaoka et al. (1994) reported that Bifidobacterium bifidum YIT 4007 improved the ethanol- and the acetic acid-induced acute gastric injuries in rats. The administration of $B$. bifidum YIT 4007 shifted the stages of peptic ulcer to the mild state and restricted the H. pylori infection on the gastric mucosa in patients (Yamamoto et al., 1994). Wang et al. (2004) demonstrated that $B$. animalis Bb12 could inhibit in vitro growth of $H$. pylori, and ingestion of this strain-containing yogurt decreased the urease activity of $H$. pylori. Furthermore, Bifidobacterium-fermented milk containing B. bifidum YIT 4007 decreased the number of Enterobacteriaceae in the human flora (Asahara et al., 1999), of which Escherichia coli can produce lots of molecular hydrogen (McKay et al., 1982). This reminds us that probiotic Bifidobacterium might change the generation of molecular hydrogen in the stomach, and subsequently affect the severity of $H$. $p y$ lori infection, because $H$. pylori uses molecular hydrogen as energy for the infection (Olson and Maier, 2002), which is frequently detected in the intragastric gas (Urita et al., 2006).

Taken these facts into consideration, we have attempted to develop a dairy food beneficial to gastric mucosal health, and then spontaneously obtained a microbiologically identical clone (BF-1) of B. bifidum YIT 4007, which has the stronger ability to survive in dairy products than this parent strain. Here, for the purpose of knowing the evaluation of the fermented milk using BF-1, we studied the effect of the ingestion of BF-1 fermented milk on $H$. pylori and gastric health in 2 in vitro assays ( $H$. pylori proliferation and IL-8 secretion) and in a human study with a randomized double-blind placebo-control design.

\section{MATERIALS AND METHODS}

\section{Bacteria}

All strains were obtained from the Culture Collection Research Laboratory of Yakult Central Institute for Microbiological Research (Tokyo, Japan). The BF-1 was kept as B. bifidum YIT 10347 in the laboratory.

\section{Sample Beverages}

The BF-1 fermented milk was prepared by anaerobic culture of these strains in sterilized milk at $37^{\circ} \mathrm{C}$ for $24 \mathrm{~h}$. The placebo was prepared from untreated milk by adjusting the organic acids (1.3 $\mathrm{mg}$ of lactic and 1.3 $\mathrm{mg}$ of acetic acids per $\mathrm{mL}$ ) to the same level as in the fermented milk. These samples were supplied as indistinguishable packaged beverages $(100 \mathrm{~mL} / 1$ bottle) to subjects at intervals of $1 \mathrm{wk}$; BF-1 beverage contained more than $1 \times 10^{7} \mathrm{cfu} / \mathrm{mL}$ of BF-1 (mostly approximately $5 \times 10^{8}$ at d 1 to approximately $1 \times 10^{8} \mathrm{cfu} / \mathrm{mL}$ at d 7 of a supplying interval) and approximately $1 \times 10^{7} \mathrm{cfu} /$ $\mathrm{mL}$ of Streptococcus thermophilus YIT 2021 (mostly constant during the interval), which was used for the adjustment of taste and flavor.

\section{Mixed Culture Assay}

Helicobacter pylori YIT 10238 was cultured in Brucella broth (Becton Dickinson Co., Sparks, MD) with $10 \%$ heat-inactivated horse serum under microaerobic $\left(5 \% \mathrm{O}_{2}, 10 \% \mathrm{CO}_{2}\right.$, and $85 \% \mathrm{~N}_{2}$ ) and mild shaking conditions at $37^{\circ} \mathrm{C}$ for $48 \mathrm{~h}$. The BF-1 was cultured in mILS medium (Shimakawa et al., 2003) under anaerobic conditions at $37^{\circ} \mathrm{C}$ for $20 \mathrm{~h}$. Portions of culture broths of $H$. pylori $\left(1 \times 10^{5} \mathrm{cfu} / \mathrm{mL}\right)$ and BF-1 $\left(1 \times 10^{7} \mathrm{cfu} / \mathrm{mL}\right)$ 
were mixed in the serum-added Brucella broth with $1 \%$ glucose and cultured under the above conditions for $H$. pylori for $48 \mathrm{~h}$. The counts of $H$. pylori and BF-1 in the mixed culture were measured on a modified Helicobacter agar plate (Nissui Pharmaceutical, Tokyo, Japan) under microaerobic conditions and TOS-propionate agar plate (Yakult Pharmaceutical, Tokyo, Japan) under anaerobic conditions, respectively.

\section{Cell Culture Assay}

The human gastric epithelial-like stomach cancer cell line GCIY RCB0555 (Nozoe et al., 1991) was obtained from the Riken Cell Bank (Tsukuba, Japan). The cells were cultured in Eagle's MEM (Nissui Pharmaceutical) supplemented with $15 \%$ fetal bovine serum (Sigma) at $37^{\circ} \mathrm{C}$ in humidified air containing $5 \% \mathrm{CO}_{2}$. Cell viability was assayed with the method of Trypan Blue exclusion (Freshney, 1987).

\section{IL-8 Assay}

The GCIY cells were seeded in the above medium (100 $\mu \mathrm{L} /$ well) onto collagen-coated 96-well plates (Sumiron, Sumitomo Bakelite, Tokyo, Japan) at a density of 4 to $5 \times 10^{5}$ cells $/ \mathrm{mL}$. The confluent cell sheet was carefully rinsed with the fresh medium once and preincubated with BF-1 or S. thermophilus YIT 2021 suspension of the medium for $3 \mathrm{~h}$. Then, the sheet was rinsed with the fresh medium 3 times and incubated with $H$. pylori $\left(1 \times 10^{7} \mathrm{cfu} / \mathrm{mL}\right)$ for $24 \mathrm{~h}$. Cell culture medium was used for $\mathrm{pH}$ measurement and IL-8 assay. The IL-8 levels were quantified with the human IL-8 immunoassay kit (Biosource International Inc., Camarillo, CA), according to the manufacturer's instructions.

\section{Subjects}

Healthy adult volunteers were recruited by Allegro Inc. (Tokyo, Japan). The content and methods of the study were fully explained to all participants, and their written informed consent was obtained in writing prior to enrollment. The study was carried out in accordance with the Declaration of Helsinki and was approved by the Clinical Examination Ethics Committee of the Arima Memorial Medical Fund (Tokyo, Japan). This human study was the pilot trial to investigate the potentials of the BF-1 fermented milk on gastric events. Eighty candidates were selected from applicants satisfying the following eligibility criteria: men and women concerned about their own stomach health, those with a urea breath test (UBT) value at $5 \%$ and over, or those judged as positive in the PG test. The sample size and UBT value were decided in consideration of the previous
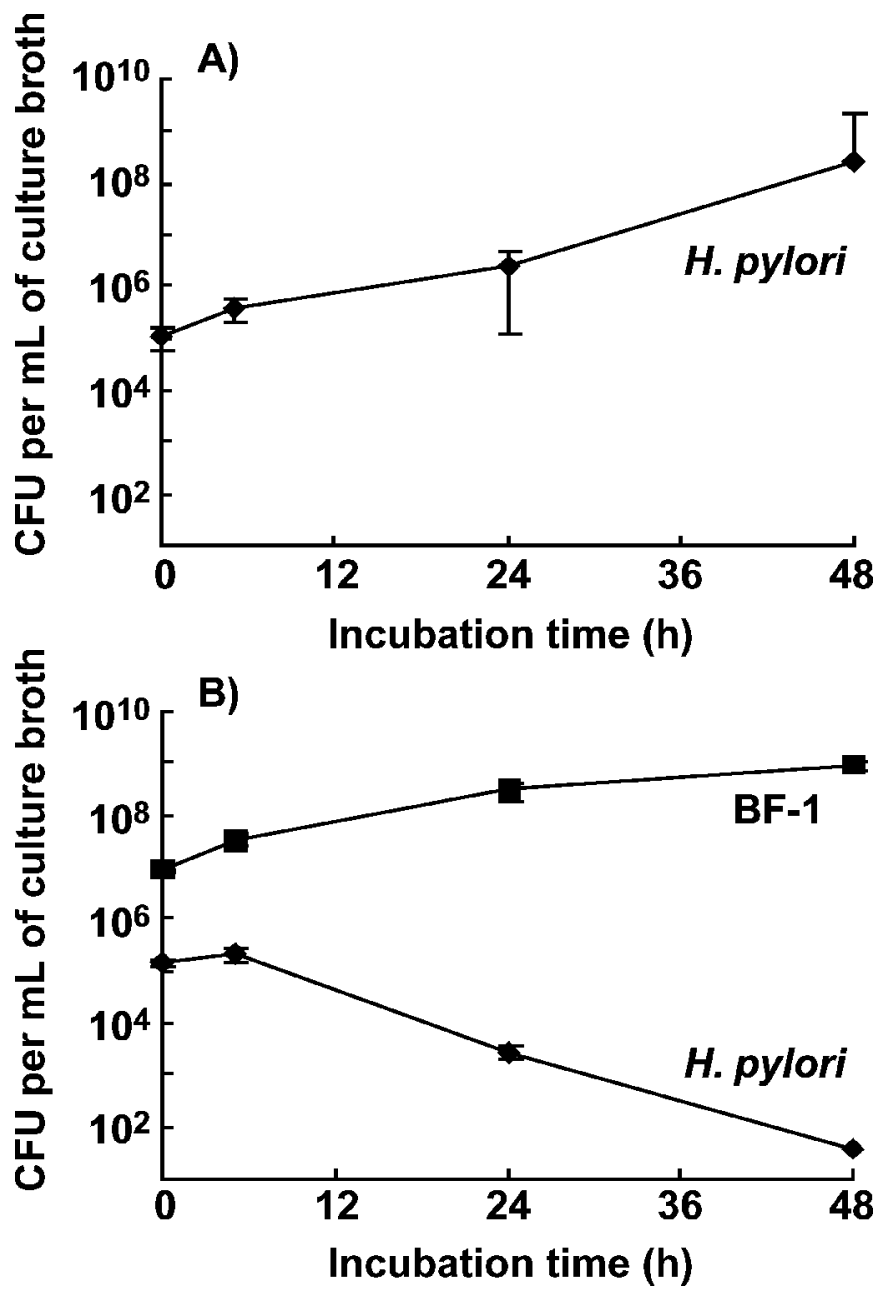

Figure 1. Growth and survival curves of Helicobacter pylori in mixed culture of BF-1. A) H. pylori alone was cultured in the Brucella broth. B) $H$. pylori and BF-1 were mixed and cultured in the broth.

reports on other probiotics (Felley et al., 2001; Pantoflickova et al., 2003). The exclusion criteria included subjects with a history of milk allergies and lactose intolerance; those with diseases, such as hepatic, biliary, circulatory, respiratory, gastrointestinal, renal, urinary, neural, mental and blood diseases; those taking antibiotics and stomach medicines such as protonpump inhibitors, bismuth salt, $\mathrm{H}_{2}$ blockers, and so on.

\section{Protocol}

A randomized double-blind placebo-controlled comparative study was performed to evaluate the effect of the BF-1 beverage. Following the entry period, the study was carried out for a period of $22 \mathrm{wk}$, which included a 2 -wk preingestion period, a 12 -wk beverageingestion period, and an 8-wk postingestion period. In 



Figure 2. Effect of BF-1 on IL-8 secretion by a human gastric cell line GCIY infected with Helicobacter pylori. Values are expressed as means $\pm \mathrm{SD}(\mathrm{n}=3)$. $P$-values are obtained from comparison with the control (H. pylori alone) using Dunnett's test.

the entry period and preingestion period, a preclinical examination and a dietary survey were carried out to screen the qualified subjects, as mentioned above. After the clinical examination during the preingestion period, the 80 subjects were randomly assigned to the BF-1 beverage-ingestion group (BF-1 group) or the placebo beverage-ingestion group (placebo group) with stratification according to age, height, weight, serum PG levels (PG I, PG II, and PG I/II ratio), and UBT values and were subjected to beverage-ingestion examination. The subjects in each group were instructed to drink one bottle of the beverage daily. After the beverage-ingestion period, the postingestion period immediately followed.

The subjects were advised not to change their current dietary habits or lifestyle and to not take foods and supplements that contained any probiotics, and which might affect $H$. pylori infection or gastric symptoms during the study period. The subjects were instructed to keep a lifestyle diary about items as follows: 1) time of ingesting the beverages; 2) description of physical conditions (disease, injury, upper and lower intestinal symptoms, bowel movement, mental activity, and complaints); and 3) description of drugs, supplements, alcohol, and smoking. Furthermore, the subjects were instructed to record the contents of all foods consumed for 3 consecutive days nutrients (protein, lipid, and carbohydrate) and the energy taken from foods in every preingestion period, beverage-ingestion period (4, 8, and $12 \mathrm{wk}$ ), and postingestion period and to record the distance walking on a pedometer for the total consumed
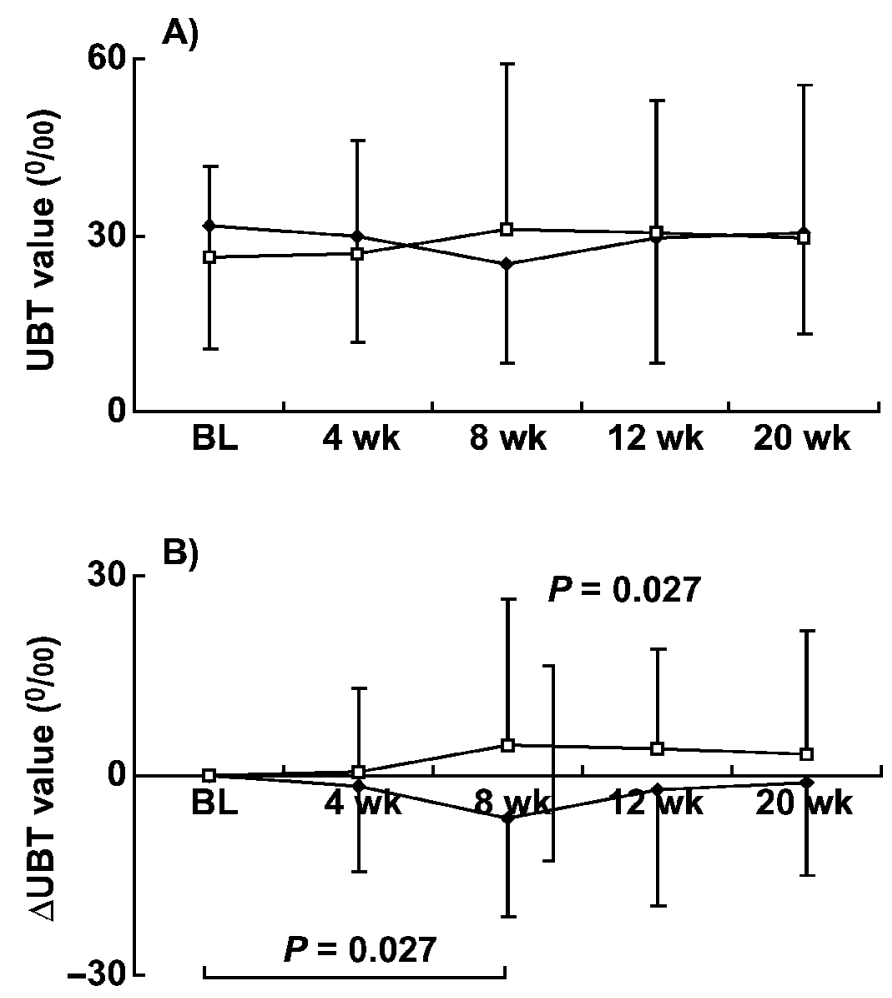

Figure 3. Urea breath test (UBT) values and the difference ( $\triangle \mathrm{UBT}$ ) between the baseline (BL) and each time in the ingestion of BF-1 fermented milk ( $\mathrm{n}=34$, closed diamond) and of the placebo milk ( $\mathrm{n}=35$, open square) among those of Helicobacter pylori-positive subjects. A) UBT value at each time. B) $\Delta \mathrm{UBT}$ values.

energy during the same period as the intake of food was recorded on the stylized dietary and physical diaries, respectively.

Clinical examination (blood test for sialic acid, aspartate transaminase, alanine transferase, $\gamma$-glutamyltransferase, alkaline phosphatase, lactate dehydrogenase, total protein, albumin, albumin:globulin ratio, total bilirubin, urea nitrogen, creatinin, uric acid, protein fractions (albumin, $\alpha 2, \beta, \gamma$, albumin:globulin ratio), total cholesterol, high-density lipoprotein, low-density lipoprotein, triglyceride, glucose, $\mathrm{Na}, \mathrm{K}, \mathrm{Ca}, \mathrm{Cl}, \mathrm{Mg}$, red blood cells, white blood cells, platelets, hematocrit, hemoglobin, mean cell hemoglobin, mean cell volume, basophil, eosinophil, lymphocyte, monocyte, neutrophil; urine test for $\mathrm{pH}$, gravity, glucose, protein, urobilinogen, ketone, hemoccult), vital sign check (systolic pressure, diastolic pressure, pulse, and body temperature), and doctor's interview for upper gastrointestinal symptoms (gastric pain, disgust, nausea, pyrosis, belch, stomach complaint) and for general health conditions were performed once (baseline) in the preingestion period, 3 times $(4,8$, and $12 \mathrm{wk})$ in the beverage-ingestion period and once (20 wk) in the postingestion period. Expiratory air for UBT analysis, blood, and urine for 




Figure 4. Correlation between urea breath test (UBT) values at baseline (BL) and the difference $(\Delta \mathrm{UBT})$ between the baseline and 8 wk (A and B) or 12 wk (C and D), in the ingestion of BF-1 fermented milk ( $\mathrm{n}=34, \mathrm{~A}$ and $\mathrm{C}$ ) and of the placebo milk ( $\mathrm{n}=35, \mathrm{~B}$ and $\mathrm{D})$. $\rho$ is Spearman's rank correlation coefficient.

clinical analysis were collected the morning after the subjects had fasted for at least $10 \mathrm{~h}$. All clinical specimens were analyzed in the General Institute of BML Inc. (Kawagoe, Japan). Two weeks after the start of the beverage-ingestion period, a subject in the placebo group retired for a personal reason independent of the study. Finally, the 79 subjects completed the study according to the protocol, in which the BF-1 group had 40 persons (sex ratio, men:women $=22: 18$; average age $=43.5 \pm 8.8 \mathrm{yr}$; age range $=24$ to $65 \mathrm{yr}$ ), and the placebo group had 39 persons (sex ratio, men:women $=$ 22:17; average age, $44.4 \pm 8.8 \mathrm{yr}$; age range, 28 to $58 \mathrm{yr}$ ).

\section{Statistical Analysis}

Data were expressed as means and SD. Data of cell culture experiment were analyzed using the Dunnett's comparison test compared with the control group. Analysis was performed using measured values of UBT and a PG test at each examination time and differences of UBT and PG values ( $\Delta$ UBT, $\Delta \mathbf{P G I}, \Delta \mathbf{P G I I}$, and $\Delta \mathbf{P G}$ I/II) between each time point and the baseline within the group, for the comparison of both beverage groups using the Mann-Whitney test and for the effect of ingestion by the Wilcoxon test using SAS version 8.2 for Windows (SAS Institute Japan, Tokyo, Japan). The correlation between the UBT value at baseline and the $\triangle \mathrm{UBT}$ at each time was analyzed with the nonparametric Spearman rank correlation using Kyplot software for Windows (Kyence Inc., Tokyo, Japan). The $\chi^{2}$ test was used for the analysis of rate of stomach symptoms between the BF-1 and placebo groups. Probability values $<0.05$ were considered to be significant. We furthermore performed stratified analysis using UBT values and serum PG levels to know what class was affected by BF-1 fermented milk. Helicobacter pylori infection was judged by the UBT value $[H$. pylori-positivity $(5 \%$ of UBT value and over: $\mathrm{n}=34$ and 35 in the BF-1 and placebo groups, respectively) and $H$. pylori-negativity (below $5 \%: \mathrm{n}=6$ and 4 in the BF-1 and placebo groups, respectively) subjects]. The serum PG test method, often used as a primary screening test for detecting gastric cancer (Miki et al., 1987, 1993, 2003), was used for the classification of the $H$. pylori-positive subjects in 
this study. In the H. pylori-positive subjects, the PG positive ( $\mathrm{n}=13$ and 10 in the BF-1 and placebo groups, respectively) with levels of PG I $<70 \mathrm{ng} / \mathrm{mL}$ and PG I/ II ratio $<3.0$ were assumed to be high-risk individuals with atrophic gastritis, and the remaining subjects (the PG negative, $\mathrm{n}=21$ and 25, respectively) were assumed to be low-risk. Furthermore, we used another classification criterion for the diagnosis of histological gastritis using the serum PG levels (Kiyohira et al., 2003). According to this criterion, the $H$. pylori-positive subjects were classified into normal stomach $(\mathrm{n}=0$ and 0 , in the BF-1 and placebo groups, respectively) with PG I $<85 \mathrm{ng} / \mathrm{mL}, \mathrm{PG}$ II $<15.0 \mathrm{ng} / \mathrm{mL}$, and PG I/II $\geq 6.5$; borderline ( $\mathrm{n}=11$ and 11 , respectively) with $\mathrm{PG} \mathrm{I}<85 \mathrm{ng} / \mathrm{mL}$, PG II $<15.0 \mathrm{ng} / \mathrm{mL}$, and PG I/II 3.0 to $<6.5$; atrophic ( $\mathrm{n}=4$ and 3 , respectively) with PG I $<85 \mathrm{ng} / \mathrm{mL}$, PG II $<15.0 \mathrm{ng} / \mathrm{mL}$, and PG I/II $<3.0$; and active gastritis ( $\mathrm{n}=$ 19 and 21, respectively) with PG I $\geq 85 \mathrm{ng} / \mathrm{mL}$ and PG II $\geq 15.0 \mathrm{ng} / \mathrm{mL}$.

\section{RESULTS}

\section{Mixed Culture Experiment}

Helicobacter pylori proliferated well in the Brucella broth, reaching more than $10^{8} \mathrm{cfu} / \mathrm{mL}$ without BF-1 (Figure 1). In the mixed culture with BF-1, H. pylori was decreased such that it could not be detected after $48 \mathrm{~h}$, but BF-1 grew slowly, accompanying the decrease in $\mathrm{pH}$ values $(\mathrm{pH} 5.51$ at $0 \mathrm{~h}, \mathrm{pH} 5.40$ at $5 \mathrm{~h}, \mathrm{pH} 5.02$ at $24 \mathrm{~h}$, and $\mathrm{pH} 4.52$ at $48 \mathrm{~h}$ ).

\section{Cell Culture Experiment}

The IL-8 secretion from GCIY cells after $H$. pylori infection was suppressed by the pretreatment with BF1 , but slightly inhibited with high dose of $S$. thermophilus YIT 2021 (Figure 2). There was no change in $\mathrm{pH}$ under this culture condition. The preincubation of BF1 or S. thermophilus YIT 2021 did not affect the viability of $H$. pylori-infected cells (data not shown).

\section{Urea Breath Test}

Of all subjects, 69 persons had more than the cutoff level of UBT at the preingestion period to be judged as positive for $H$. pylori infection. The BF-1 group had low UBT values in the beverage-ingestion period compared with baseline; the UBT value at 8 wk was lower $(P=$ 0.029 ) than that at baseline (Figure 3). However, the placebo group had high UBT values. The $\triangle$ UBT value of the BF-1 group was lower than that of the placebo group at 8 wk $(P=0.027)$. Furthermore, the UBT values of the preingestion period showed a negative correlation with $\triangle \mathrm{UBT}$ values at $8 \mathrm{wk}(\rho=-0.533, P=0.002)$ and
12 wk ( $\rho=-0.360, P=0.039$ ) in the BF-1 group but not in the placebo group (Figure 4). Next, the 2 beverage groups were compared with 2 criteria for their serum PG levels. First, the $\Delta \mathrm{UBT}$ values of the BF-1 group were lower than those of the placebo group at $8 \mathrm{wk}(P=$ $0.010)$ and $12 \mathrm{wk}(P=0.088)$ in the PG-positive class (Figure 5), but not different in the PG-negative class. Second, the $\triangle \mathrm{UBT}$ values of the BF-1 group were lower than those of the placebo group at 8 wk $(P=0.011)$ and 12 wk $(P=0.028)$ in the active gastritis class (Figure 6 ), but were not different in the other classes (data not shown).

\section{Serum Pepsinogen Concentration}

The PG I levels of both groups during the ingestion period were not different from baseline, but those of the placebo group rose along after completion of the ingestion ( $P=0.020$ at $20 \mathrm{wk}$; Figure $7 \mathrm{~A}$ and $7 \mathrm{~B})$. The $\mathrm{BF}-1$ group was lower than in the placebo group in $\mathrm{PG}$ I level at $12 \mathrm{wk}(P=0.038)$ and $\triangle \mathrm{PG} \mathrm{I}$ level at $12 \mathrm{wk}$ $(P=0.087)$. In the BF-1 group the PG II levels did not change during the beverage-ingestion period but rose after the cessation of ingestion $(P=0.001$ at $20 \mathrm{wk}$; Figure $7 \mathrm{C}$ and $7 \mathrm{D})$. The PG II levels of the placebo group were increased even during the ingestion period $(P=0.025$ at $12 \mathrm{wk})$ and at the postingestion period $(P$ $<0.001$ at $20 \mathrm{wk}$ ). However, no group difference in the PG II and $\triangle \mathrm{PG}$ II levels was observed. The PG I/II ratios decreased at $12 \mathrm{wk}(P<0.001$ and $P=0.039)$ and $20 \mathrm{wk}(P<0.001$ and $P=0.003)$ compared with the baseline in the BF-1 and placebo groups, respectively, but no group differences were observed (Figure $7 \mathrm{E}$ and $7 \mathrm{~F})$. Furthermore, in the $H$. pylori-positive subjects, the group difference of the $\triangle \mathrm{PG}$ I levels could not be shown $(P=0.138$ at $12 \mathrm{wk})$, whereas the $\triangle \mathrm{PG}$ II levels (BF-1, $P<0.001$ at $20 \mathrm{wk}$; placebo, $P=0.022$ at $12 \mathrm{wk}$ and $P<0.001$ at $20 \mathrm{wk})$ and the $\triangle \mathrm{PG} \mathrm{I} / \mathrm{II}$ ratios (BF-1, $P=0.002$ at $12 \mathrm{wk}$ and $P<0.001$ at $20 \mathrm{wk}$; placebo, $P=0.017$ at $12 \mathrm{wk}$ and $P=0.001$ at $20 \mathrm{wk}$ ) showed similar patterns as observed in Figure 7D and $7 \mathrm{~F}$.

\section{Upper Gastrointestinal Symptoms}

Twenty-eight subjects $(\mathrm{n}=14$, men:women $=5: 9$ in the BF-1 group; $n=14$, men:women $=5: 9$ in the placebo group) had one or more upper gastrointestinal symptoms according to doctors' interviews at the preingestion period. As for the rate of the number of symptomrelieved subjects, the BF-1 group (4 wk, 79\%, $\mathrm{n}=11$; $8 \mathrm{wk}, 79 \%, \mathrm{n}=11 ; 12 \mathrm{wk}, 93 \%, \mathrm{n}=13 ; 20 \mathrm{wk}, 93 \%, \mathrm{n}=$ 13) was higher ( $4 \mathrm{wk}, P=0.022 ; 8$ wk, $P=0.115 ; 12$ wk, $P=0.065 ; 20 \mathrm{wk}, P=0.001$ ) than the placebo group 

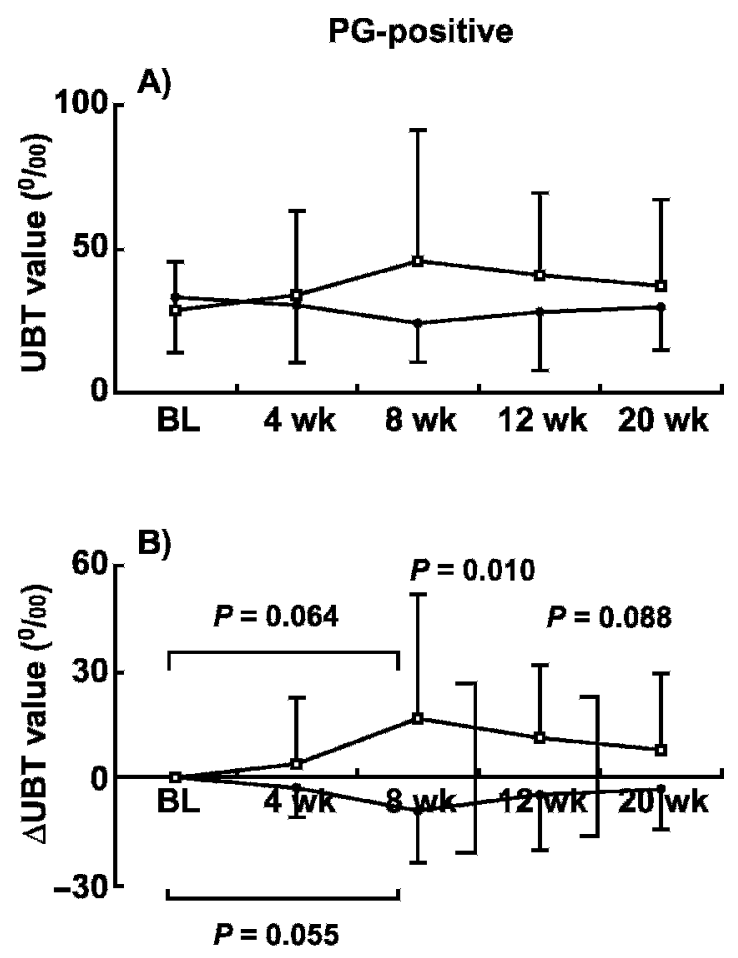

PG-negative
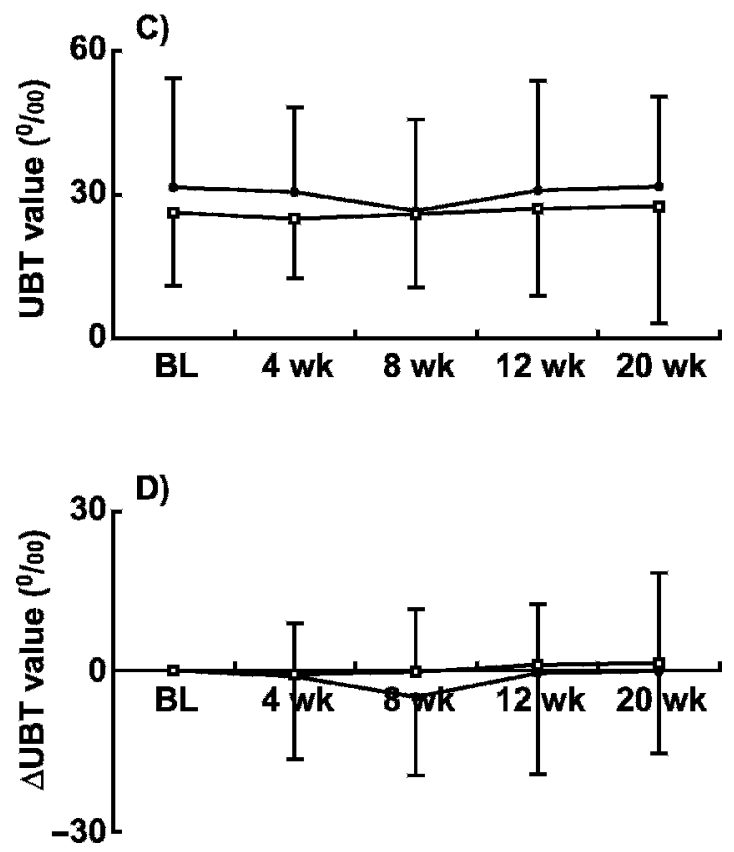

Figure 5. Urea breath test (UBT) values and the difference ( $\triangle \mathrm{UBT}$ ) between baseline (BL) and each time in the ingestion of BF1 fermented milk ( $\mathrm{n}=13$, closed diamond) and of the placebo milk $(\mathrm{n}=10$, open square) in the pepsinogen (PG) test method positive subjects (A and B), and in the ingestion of BF-1 fermented milk ( $\mathrm{n}=$ 21 , closed diamond) and of the placebo milk ( $\mathrm{n}=25$, open square) in the PG-negative subjects (C and D). A and $\mathrm{C}$, UBT values at each time. $\mathrm{B}$ and $\mathrm{D}, \triangle \mathrm{UBT}$ values. Identification of PG-positive and PGnegative subjects was as described in Materials and Methods.
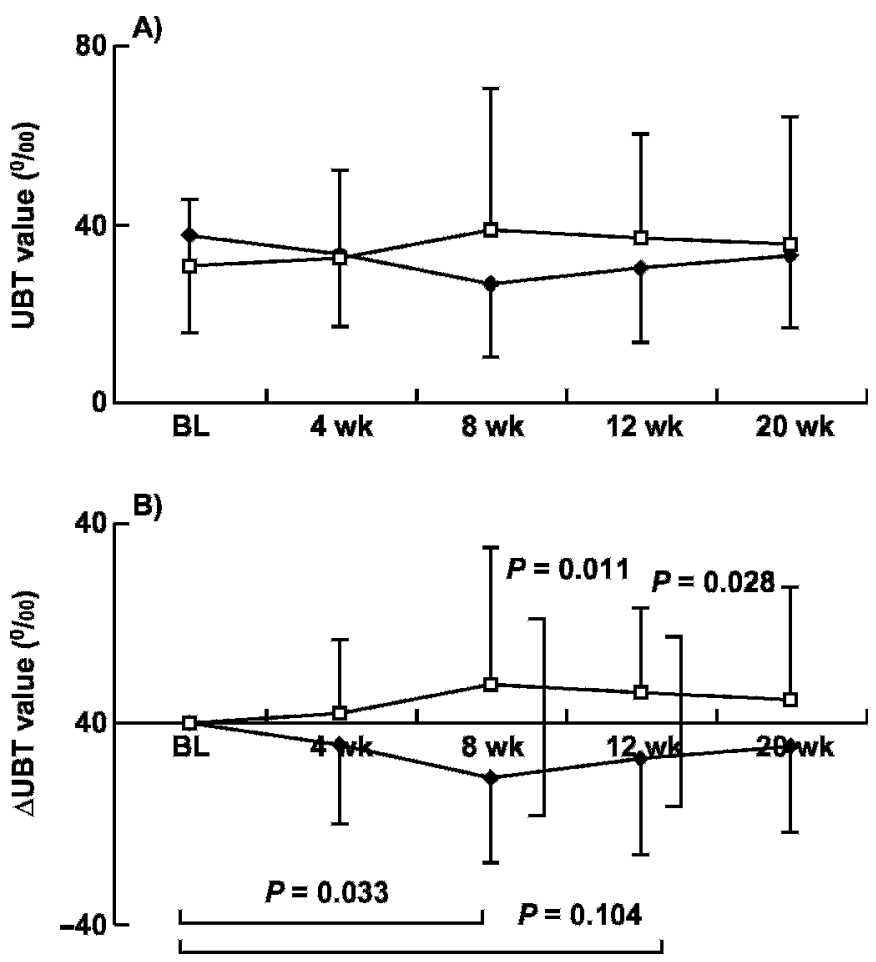

Figure 6. Urea breath test (UBT) values, and the difference ( $\triangle \mathrm{UBT}$ ) between baseline (BL) and each time in the ingestion of BF1 fermented milk ( $\mathrm{n}=19$, closed diamond) and of the placebo milk ( $\mathrm{n}=21$, open square) in the active gastritis subjects classified by serum pepsinogen levels. A) UBT values at each time. B) $\Delta$ UBT values. Identification of active gastritis subjects was as described in Materials and Methods.

( $4 \mathrm{wk}, 36 \%, \mathrm{n}=5 ; 8 \mathrm{wk}, 50 \%, \mathrm{n}=7 ; 12 \mathrm{wk}, 64 \%, \mathrm{n}=$ $9 ; 20 \mathrm{wk}, 36 \%, \mathrm{n}=5)$. Thirty-five symptoms (BF-1, $\mathrm{n}=$ 18; placebo, $\mathrm{n}=17$ ) were apparent in 28 symptomatic subjects. Regarding the rate of total numbers of improved symptoms, the BF-1 group ( $4 \mathrm{wk}, 78 \%, \mathrm{n}=14$; $8 \mathrm{wk}, 78 \%, \mathrm{n}=14 ; 12 \mathrm{wk}, 89 \%, \mathrm{n}=16 ; 20 \mathrm{wk}, 83 \%, \mathrm{n}=$ 15) was higher ( $4 \mathrm{wk}, P=0.004 ; 8 \mathrm{wk}, P=0.027 ; 12$ wk, $P=0.042 ; 20 \mathrm{wk}, P=0.004)$ than the placebo group ( $4 \mathrm{wk}, 29 \%, \mathrm{n}=5 ; 8 \mathrm{wk}, 41 \%, \mathrm{n}=7 ; 12 \mathrm{wk}, 59 \%, \mathrm{n}=$ $10 ; 20 \mathrm{wk}, 35 \%, \mathrm{n}=6)$.

\section{Clinical Examination}

Among the vital signs, clinical laboratory values, results of doctors' interviews, and contents of the lifestyle diary in the study period, there was no problem derived from ingestion of beverages. The nutrients, total energy obtained from foods, and total energy consumed from walking were not different between the BF-1 and placebo groups.

\section{DISCUSSION}

Some probiotics have potential activity on the inhibition of $H$. pylori in vitro and in vivo and the improve- 

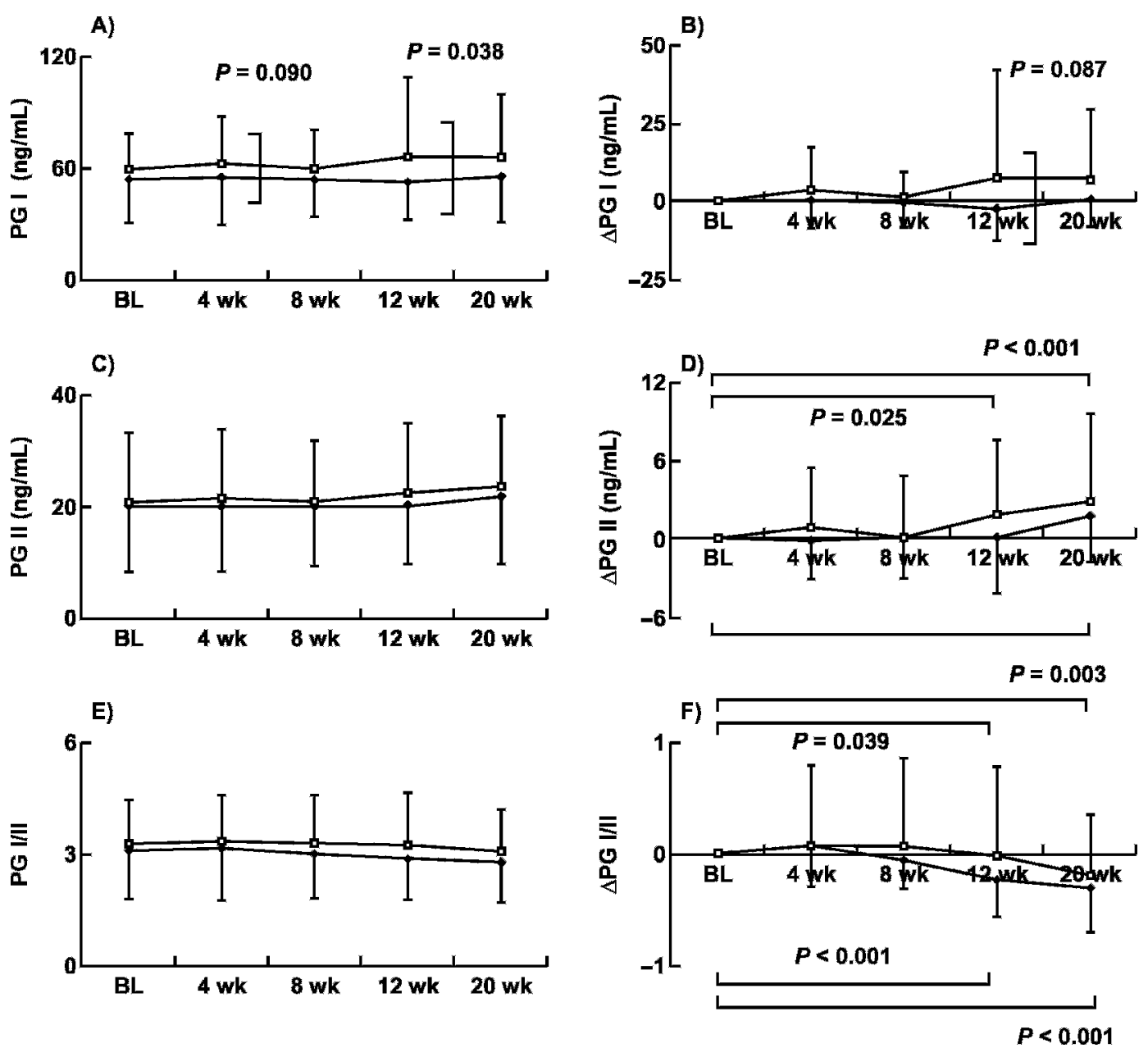

Figure 7. The pepsinogen (PG) I levels, PG II levels, and PG I/II ratios, and the differences ( $\Delta \mathrm{PG}$ I, $\Delta \mathrm{PG}$ II and $\Delta \mathrm{PG}$ I/II) between baseline (BL) and each time in the ingestion of BF-1 fermented milk $(\mathrm{n}=40$, closed diamond) and of the placebo milk ( $\mathrm{n}=39$, open square). A) PG I levels at each time; B) $\Delta$ PG I levels; C) PG II levels at each time; D) $\Delta$ PG II levels; E) PG I/II ratios at each time; F) $\Delta$ PG I/II ratios.

ment of gastritis in H. pylori infection (Hamilton-Miller, 2003). To be previously reported, B. bifidum YIT 4007 alleviated drug-induced acute injury in the rat stomach (Nagaoka et al., 1994) and improved the stage of disease in peptic ulcer patients (Yamamoto et al., 1994). To understand the potential interference to $H$. pylori infection, we investigated the effect of a new clone, BF-1, on the pathogen growth in vitro and the efficacy of the fermented milk on the $H$. pylori and serum gastric markers in vivo in humans.

The BF-1 inhibited the $H$. pylori growth in mixed culture under suitable conditions of $H$. pylori. The pattern of decrease in $H$. pylori is similar to the pattern of $\mathrm{pH}$ decrease. Live $H$. pylori was not detected after $48 \mathrm{~h}$ ( $\mathrm{pH} 4.5$ ), but BF-1 was proliferated. This indicated that BF- 1 could restrict the activity of $H$. pylori (growth, survival, or action) through the action of organic acids like lactic and acetic acids as metabolic products. How- ever, some bifidobacteria could produce heat-stable antimicrobial peptides against $H$. pylori (Collado et al., 2005 ), and then a strain of $B$. bifidum produces a bacteriocin, bifidocin $\mathrm{B}$, which has not been reported for $H$. pylori (Yildirim and Johnson, 1998). Therefore, it would be necessary to consider other factors than organic acids for the inhibition of $H$. pylori.

Helicobacter pylori-associated gastritis is histologically characterized by infiltration of neutrophils, lymphocytes, and macrophages into the mucosa (Rauws et al., 1988), accompanying expression of various cytokines (Yamaoka et al., 1997). The IL-8 is the potent chemotactic activity for neutrophils (Crabtree et al., 1994), and its level in the mucosa is closely correlated with the density of $H$. pylori and neutrophil infiltration in the antrum (Yamaoka et al., 1998). The BF-1 suppressed the $H$. pylori-induced IL-8 secretion from GCIY cells, where $\mathrm{pH}$ values and cell viability were constant 
during the experiment. These results showed that organic acids were not major inhibitory factors for IL-8 secretion and that cell injury was not associated with the suppression. The BF-1 had the ability to adhere to GCIY cells, and the treatment of BF-1 after the infection did not suppress the IL-8 secretion due to $H$. pylori (unpublished data). These findings indicate that the interaction of BF- 1 with the gastric cells before $H$. pylori infection might be essential for the suppression of IL8 secretion.

Their ingestion of BF-1 fermented milk affected the $H$. pylori biomarker values in the $H$. pylori-positive population, but the placebo did not. Some probiotics reported to be active against $H$. pylori show the activity to decrease the UBT biomarker values in the human study (Sakamoto et al., 2001; Cruchet et al., 2003; Pantoflickova et al., 2003; Linsalata et al., 2004; Wang et al., 2004), but there have been no reports about the eradication of the pathogen, as seen in our study. The efficacy of BF-1 fermented milk was clearer in the active gastritis class with higher levels of PG I and PG II, the $\mathrm{BF}-1$ group was lower in $\triangle \mathrm{UBT}$ values than the placebo group; this class is characterized as $100 \%$ infection of $H$. pylori and higher incidences of active inflammation assessed by neutrophil infiltration and chronic inflammation by mononuclear cell infiltration (Kiyohira et al., 2003). The results indicate that BF-1 fermented milk could suppress $H$. pylori activity during ingestion, which might calm the gastric inflammation.

Furthermore, we observed that subjects with higher UBT values at baseline had more significant rates of reduction after ingestion of BF-1 fermented milk (Figure 4). Because of correlations of UBT values with the histological grade of $H$. pylori colonization (Perri et al., 1998) and with the density of $H$. pylori genomes (Kobayashi et al., 2002) in the gastric mucosa, higher UBT subjects were predicted as higher $H$. pylori carriers, which are presumably exposed to higher risk for stomach diseases and disorders. Our finding indicates that BF-1 fermented milk might effectively suppress the higher risk of the pathogens, but it remains speculative.

The BF-1 fermented milk contained S. thermophilus YIT 2021, in addition to BF-1. Because there were considerable numbers of live $S$. thermophilus (1/50 to $1 / 10$ cfu of BF-1) in the BF-1 fermented milk, this bacterium had possibilities to partially participate in the effect, but we have not known yet whether it affects gastric events. It would be important and inevitable to clarify contribution rate of each strain to better understand the mechanism of the anti- $H$. pylori activity of BF-1 fermented milk.

Helicobacter pylori infection increases in serum PG I and PG II levels (Kuiphers et al., 1995; Asaka et al.,
1992; Knight et al., 1995; Ohkusa et al., 2004) and is well correlated with inflammatory scores (Wagner et al., 1994; Lopes et al., 2006). Especially, the PG II level is increased compared with the PG I level, proposing the use as a marker of $H$. pylori infection or eradication and of histological features of the gastric body (Miki et al., 2003; Kiyohira et al., 2003; di Mario et al., 2004). During the ingestion of BF-1, the serum PG II levels were maintained at baseline level, but they were increased after the completion of ingestion. This pattern of the PG II levels is the case of the H. pylori-positive subjects. The results show that the ingestion of BF-1 fermented milk might affect the development of inflammation in the stomach. The PG I/II ratio was decreased by both samples in the whole and $H$. pyloripositive subjects. The successful eradication of $H$. pylori decreases the PG I and PG II and increases the PG I/ II ratio (Hunter et al., 1993; Haruma et al., 1999). The BF-1 fermented milk did not eradicate $H$. pylori; therefore, the decrease in the PG I/II ratio might be not observed despite the suppression of the PG I and PG II levels. Although these observations could help to presume the effect of the BF-1 fermented milk on the gastric mucosa infected by $H$. pylori, because we have not observed any group differences in pepsinogen levels in the $H$. pylori-positive subjects in this study, further investigations using histological approaches would be required to clarify the direct effects of BF-1 on the mucosa.

The BF-1 fermented milk increased the number of subjects with relief from gastrointestinal symptoms, improved gastrointestinal symptoms during the ingestion period, and increased the feeling of relief following complete ingestion. The symptoms or complaints are not always linked with clear pathophysiological abnormalities (Colin-Jones and a working party, 1988), in which $H$. pylori infection is a risk factor for dyspepsia along with complaints (Suzuki et al., 2005; WildnerChristensen et al., 2006). To know whether the improving effect of BF-1 fermented milk is related with $H$. pylori infection, therefore, a larger scale intervention study targeting $H$. pylori-negative as well as $H$. pyloripositive subjects would be necessary.

Helicobacter pylori infection is a serious risk for the incidence of upper gastrointestinal diseases, such as peptic ulcer, atrophic gastritis, and stomach cancers. In many cases, the carriers remained asymptomatic, not compelled to cure the pathogen, despite their own risky situation. Therefore, it is important to remove or suppress $H$. pylori activity and toxicity using various anti-H. pylori techniques other than drugs, such as probiotics or functional foods against $H$. pylori. Some probiotics are useful for suppressing $H$. pylori infection, relieving stomach symptoms, and improving gastric in- 
flammation. We reported here that the ingestion of $\mathrm{BF}$ 1 fermented milk affected 1) the UBT values of $H$. $p y$ lori-positive subjects, 2) the serum PG I and PG II levels, and 3) the upper gastrointestinal symptoms, indicating that the fermented milk with probiotics might be useful for the maintenance of stomach health.

\section{ACKNOWLEDGMENTS}

We thank T. Shibuya and Alegro (Tokyo, Japan) staff for the coordination and performance of the human study and K. Hirabayashi of MIC Medical (Tokyo, Japan) for data analysis. We thank M. Onoue of the Yakult Central Institute for his kind advice and discussion. We thank the staff of the Institute and the Faculty of Research and Development of Yakult Honsha for manufacturing the BF-1 fermented milk.

\section{REFERENCES}

Asahara, T., K. Shimizu, Y. Ohashi, T. Matsuki, K. Matsumoto, T. Takada, N. Yuki, H. Takayama, and R. Tanaka. 1999. The effects of bifidobacteria-fermented milk on human urinary mutagenicity, which increases following ingestion of cooked ground beef. J. Intest. Microbiol. 12:89-96. (in Japanese)

Asaka, M., T. Kimura, M. Kudo, H. Terada, S. Mitani, T. Miyazaki, K. Miki, and D. Y. Graham. 1992. Relationship of Helicobacter pylori to serum pepsinogens in an asymptomatic Japanese population. Gastroenterology 102:760-766.

Coconnier, M. H., V. Lievin, E. Hermery, and A. L. Servin. 1998. Antagonistic activity against Helicobacter infection in vitro and in vivo by the human Lactobacillus acidophilus strain LB. Appl. Environ. Microbiol. 64:4373-4380.

Colin-Jones, D. G., and a working party. 1988. Management of dyspepsia: Report of a working party. Lancet I:576-579.

Collado, M. C., A. González, R. González, M. Hernández, M. A. Ferrús, and Y. Sanz. 2005. Antimicrobial peptides are among the antagonistic metabolites produced by Bifidobacterium against Helicobacter pylori. Int. J. Antimicrob. Agents. Food Microbiol. 25:385-391.

Crabtree, J. E., J. I. Wyatt, L. K. Trejdosiewicz, P. Peichl, P. H. Nichols, N. Ramsay, J. N. Primrose, and I. J. Lindley. 1994. Interleukin-8 expression in Helicobacter pylori infected, normal, and neoplastic gastroduodenal mucosa. J. Clin. Pathol. 47:61-66.

Cruchet, S., M. C. Obregon, G. Salazar, E. Diaz, and M. Gottenland. 2003. Effect of the ingestion of a dietary product containing Lactobacillus johnsonii La1 on Helicobacter pylori colonization in children. Nutrition 19:716-721.

de Vrese, M., and J. Schrezenmeir. 2002. Probiotics and non-intestinal infectious conditions. Br. J. Nutr. 88(Suppl.):S59-S66.

di Mario, F., A. M. Moussa, L. G. Cavallaro, P. Caruana, R. Merli, S. Bertolini, V. Iori, G. M. Cavestro, N. Dal Bo, A. Pilotto, A. Franz, and G. Leandro. 2004. Clinical usefulness of serum pepsinogen II in the management of Helicobacter pylori infection. Digestion 70:167-172.

Felley, C. P., I. Corthésy-Theulaz, J.-L. B. Rivero, P. Sipponen, M. Kaufmann, P. Bauerfeind, P. H. Wiesel, D. Barassart, A. Pfeifer, A. L. Blum, and P. Michetti. 2001. Favourable effect of an acidified milk (LC-1) on Helicobacter pylori gastritis in man. Eur. J. Gastroenterol. Hepatol. 13:25-29.

Freshney, R. 1987. Culture of Animal Cells. Page 117 in A Manual of Basic Technique. Alan R. Liss Inc., New York, NY.

Fuller, R. 1991. Probiotics in human medicine. Gut 32:439-442.

Hamada, H., K. Haruma, M. Mihara, T. Kameda, M. Yoshihara, K. Sumii, G. Kajiyama, and M. Kawanishi. 2000. High incidence of reflux oesphagitis after eradication therapy for Helicobacter pylori: Impacts of hiatal hernia and corpus gastritis. Aliment. Pharmacol. Ther. 14:729-735.

Hamilton-Miller, J. M. T. 2003. The role of probiotics in the treatment and prevention of Helicobacter pylori infection. Int. J. Antimicrob. Agents 22:360-366.

Haruma, K., M. Mihara, E. Okamoto, H. Kusunoki, M. Hananlki, S. Tanaka, M. Yoshihara, K. Sumii, and G. Kajiyama. 1999. Eradication of Helicobacter pylori increases gastric acidity in patients with atrophic gastritis of the corpus-Evaluation of 24-h $\mathrm{pH}$ monitoring. Aliment. Pharmacol. Ther. 13:155-162.

Hunter, F. M., P. Correa, E. Fontham, B. Ruiz, M. Sobhan, and I. M. Samloff. 1993. Serum pepsinogens as markers of response to therapy for Helicobacter pylori gastritis. Dig. Dis. Sci. 38:20812086.

Kawaguchi, H., K. Haruma, K. Komoto, M. Yoshihara, and G. Kajiyama. 1996. Helicobacter pylori infection is the major risk factor for atrophic gastritis. Am. J. Gastroenterol. 91:959-962.

Kiyohira, K., M. Yoshihara, M. Ito, K. Hamura, S. Tanaka, and K. Chayama. 2003. Serum pepsinogen concentration as a marker of Helicobacter pylori infection and the histologic grade of gastritis; evaluation of gastric mucosa by serum pepsinogen levels. J. Gastroenterol. 38:332-338.

Knight, T., S. Greaves, A. Wilson, K. Hengels, D. Newell, M. Corlett, P. Webb, D. Forman, and J. Elder. 1995. Variability in serum pepsinogen levels in an asymptomatic population. Eur. J. Gastroenterol. Hepatol. 7:647-654.

Kobayashi, D., Y. Eishi, T. Ohkusa, I. Ishige, T. Suzuki, J. Minami, T. Yamada, T. Takizawa, and M. Koike. 2002. Gastric mucosal density of Helicobacter pylori estimated by real-time PCR compared with results of urea breath test and histological grading. J. Med. Microbiol. 51:305-311.

Kuiphers, E. J., A. M. Uyterlinde, A. S. Pena, R. Roosendaal, G. Pals, G. F. Nelis, H. P. Festen, and S. G. Meuwissen. 1995. Long-term sequelae of Helicobacter pylori gastritis. Lancet 345:1525-1528.

Lind, T., F. Megraud, P. Unge, E. Bayerdorffer, C. O'Morain, R. Spiller, S. V. van Zanten, K. D. Bardhan, M. Hellblom, M. Wrangstadh, L. Zeijlon, and C. Cederberg. 1999. The MACH 2 study: Role of omeprazole in eradication of Helicobacter pylori with 1week triple therapies. Gastroenterology 116:248-253.

Linsalata, M., F. Russo, P. Berloco, M. L. Caruso, G. D. Matteo, M. G. Cifone, C. D. Simone, E. Ierardi, and A. Di Leo. 2004. The influence of Lactobacillus brevis on ornitine decarboxylase activity and polyamine profiles in Helicobacter pylori-infected gastric mucosa. Helicobacter 9:165-172.

Lopes, A. I., A. Palha, T. Lopes, L. Monteiro, M. Oleastro, and A. Fernandes. 2006. Relationship among serum pepsinogens, serum gastrin, gastric mucosal histology and $H$. pylori virulence factors in a paediatric population. Scand. J. Gastroenterol. 41:524-531.

Malfertheiner, P., F. Mégraud, C. O'Morain, A. P. Hungin, R. Jones, A. Axon, D. Y. Graham, and G. Tytgat; European Helicobacter Pylori Study Group (EHPSG). 2002. Current concepts in the management of Helicobacter pylori infection-The Maastricht 22000 Consensus report. Aliment. Pharmacol. Ther. 16:167-180.

Mascitelli, L., and F. Pezzetta. 2003. Quadruple treatments for Helicobacter pylori. Lancet 361:86.

Matsumoto, S., Y. Washizuka, Y. Matsumoto, S. Tawara, F. Ikeda, Y. Yokota, and M. Karita. 1997. Appearance of metronidazoleresistant Helicobacter pylori strain in an infected ICR-mouse model and difference in eradication of metronidazole-resistant and -sensitive strains. Antimicrob. Agents Chemother. 41:2602-2605.

McKay, L. F., W. P. Holbrook, and M. A. Eastwood. 1982. Methane and hydrogen production by human intestinal anaerobic bacteria. Acta Pathol. Microbiol. Immunol. Scand. Sect. B. 90:257-260.

Midolo, P. D., J. R. Lambert, R. Hull, F. Luo, and M. L. Grayson. 1995. In vitro inhibition of Helicobacter pylori NCTC 11637 by organic acids and lactic acid bacteria. J. Appl. Bacteriol. 79:475-479.

Miki, K. 2001. Pepsinogen Test Method Handbook. Medical View Inc., Tokyo, Japan. 
Miki, K., M. Ichinose, K. B. Ishikawa, N. Yanagi, M. Matsushima, N. Kakei, S. Tsukada, M. Kido, S. Ishikawa, Y. Shimizu, T. Suzuki, and K. Kurokawa. 1993. Clinical application of serum pepsinogen I and II levels for mass screening to detect gastric cancer. Jpn. J. Cancer Res. 84:1086-1090.

Miki, K., M. Ishinose, A. Shimizu, S. C. Huang, H. Oka, C. Furihata, T. Matsushima, and K. Takahashi. 1987. Serum pepsinogens as a screening test of extensive chronic gastritis. Gastroenterol. Jpn. 22:133-141.

Miki, K., M. Morita, M. Sasajima, R. Hoshina, E. Kanda, and Y. Urita. 2003. Usefulness of gastric cancer screening using the serum pepsinogen test method. Am. J. Gastroenterol. 98:735-739.

Morris, A., and G. Nicholson. 1987. Infection of Campylobacter pylori causes gastritis and raised fasting gastric $\mathrm{pH}$. Am. J. Gastroenterol. 82:192-199.

Nagaoka, M., S. Hashimoto, T. Watanabe, T. Yokokura, and Y. Mori. 1994. Anti-ulcer effects of lactic acid bacteria and their cell wall polysaccharides. Biol. Pharm. Bull. 17:1012-1017.

Nozoe, M., M. Nishida, T. Todoroki, and Y. Iwasaki. 1991. Establishment and characterization of a human scirrhus type gastric cancer cell line, GCIY, producing CA19-9. Hum. Cell 4:71-75.

Oderda, G. 2003. Results of data collected by the Paediatric European Register for treatment of Helicobacter pylori (PERTH). Helicobacter 8:452.

Ohkusa, T., H. Miwa, T. Nomura, D. Asaoka, A. Kurosawa, N. Sakamoto, S. Abe, M. Hojo, T. Terai, T. Ogihara, and N. Sato. 2004. Improvement in serum pepsinogens and gastrin in long-term monitoring after eradication of Helicobacter pylori: Comparison with $H$. pylori-negative patients. Aliment. Pharmacol. Ther. 20(Suppl. 1):25-32.

Olson, J. W., and R. J. Maier. 2002. Molecular hydrogen as an energy source for Helicobacter pylori. Science 298:1788-1790.

Pantoflickova, D., I. Corthésy-Theulaz, G. Dorta, M. Stolte, P. Isler, F. Rochat, M. Enslen, and A. L. Blum. 2003. Favourable effect of regular intake of fermented milk containing Lactobacillus johnsonii on Helicobacter pylori-associated gastritis. Aliment. Pharmacol. Ther. 18:805-813.

Perri, F., R. Clemente, M. Pastore, M. Quitadamo, V. Festa, M. Bisceglia, M. Li Bergoli, G. Lauriola, G. Leandro, Y. Ghoos, P. Rutgeerts, and A. Andriulli. 1998. The 13C-urea breath test as a predictor of intragastric bacterial load and severity of Helicobacter pylori gastritis. Scand. J. Clin. Lab. Invest. 58:19-27.

Rauws, E. A., W. Langenberg, H. J. Houthoff, H. C. Zanen, and G. N. Tytgat. 1988. Campylobacter pyloridis-associated chronic active antral gastritis. A prospective study of its prevalence and the effects of antibacterial and antiulcer treatment. Gastroenterology 94:33-40.

Sakamoto, I., M. Igarashi, K. Kimura, A. Takagi, T. Miwa, and Y. Koga. 2001. Suppressive effect of Lactobaccilus gasseri OLL 2716 (LG21) on Helicobacter pylori infection in humans. J. Antimicrob. Chemother. 47:709-710.

Samloff, I. M., K. Varis, T. Ihamaki, M. Siurala, and J. I. Rotter. 1982. Relationships among serum pepsinogen I, serum pepsinogen II, and gastric mucosal histology. A study in relatives of patients with pernicious anemia. Gastroenterol. 83:204-209.

Sgouras, D., P. Maragkoudakis, K. Petraka, B. Martinez-Gonzalez, E. Eriotou, S. Michopoulos, G. Kalantzopoulos, E. Tsakalidou, and A. Mentis. 2004. In vitro and in vivo inhibition of Helicobacter pylori by Lactobacillus casei strain Shirota. Appl. Environ. Microbiol. 70:518-526.

Sgouras, D., E. G. Panayotopoulou, B. Martinez-Gonzalez, K. Petraki, S. Michopoulos, and A. Mentis. 2005. Lactobacillus johnsonii La1 attenuates Helicobacter pylori-associated gastritis and reduces levels of proinflammatory chemokines in C57BL/6 mice. Clin. Diagn. Lab. Immunol. 12:1378-1386.

Shimakawa, Y., S. Matsubara, N. Yuki, M. Ikeda, and F. Ishikawa 2003. Evaluation of Bifidobacterium breve strain Yakult-fermented soymilk as a probiotic food. Intern. J. Food Microbiol. 81:131-136.

Suzuki, H., T. Masaoka, G. Sakai, H. Ishii, and T. Hibi. 2005. Improvement of gastrointestinal quality of life scores in cases of Helicobacter pylori-positive functional dyspepsia after successful eradication therapy. J. Gastroenterol. Hepatol. 20:1652-1660.

Tamura, A., H. Kumai, N. Nakamura, T. Nakamichi, T. Sugiyama, R. Deguchi, A. Takagi, and Y. Koga. 2006. Suppression of Helicobacter pylori-induced interleukin-8 production in vitro and within the gastric mucosa by a live Lactobacillus strain. J. Gastroenterol. Hepatol. 21:1399-1406.

Uemura, N., T. Mukai, S. Okamoto, S. Yamaguchi, H. Mashiba, K. Taniyama, N. Sasaki, K. Haruma, K. Sumii, and G. Kajiyama. 1997. Effect of Helicobacter pylori eradication on subsequent development of cancer after endoscopic resection of early gastric cancer. Cancer Epidemiol. Biomarks Prev. 6:639-642.

Uemura, N., S. Okamoto, S. Yamamoto, N. Matsumura, S. Yamaguchi, M. Yamakido, K. Taniyama, N. Sasaki, and R. J. Schlemper. 2001. Helicobacter pylori infection and the development of gastric cancer. N. Engl. J. Med. 345:784-789.

Urita, Y., S. Ishihara, T. Akimoto, H. Kato, N. Hara, Y. Honda, Y. Nagai, K. Nakanishi, N. Shimada, M. Sugimoto, and K. Miki. 2006. Hydrogen and methane gases are frequently detected in the stomach. World J. Gastroenterol. 12:3088-3091.

Wagner, S., K. Haruma, U. Gladziwa, B. Soudah, M. Gebel, J. Bleck, H. Schmidt, and M. Manns. 1994. Helicobacter pylori infection and serum pepsinogen A, pepsinogen $\mathrm{C}$, and gastrin in gastritis and peptic ulcer: Significance of inflammation and effect of bacterial eradication. Am. J. Gastroenterol. 89:1211-1218.

Wang, K.-Y., S.-N. Li, C.-S. Liu, D.-S. Perng, Y.-C. Su, D.-C. Wu, C.M. Jan, C.-H. Huang, T.-N. Wang, and W.-M. Wang. 2004. Effects of ingesting Lactobacillus- and Bifidobacterium-containing yogurt in subjects with colonized Helicobacter pylori. Am. J. Clin. Nutr. 80:737-741.

Wildner-Christensen, M., J. M. Hansen, and O. B. De Muckadell. 2006. Risk factors for dyspepsia in a general population: Nonsteroidal anti-inflammatory drugs, cigarette smoking and unemployment are more important than Helicobacter pylori infection. Scand. J. Gastroenterol. 41:149-154.

Yamamoto, Y., S. Sakurabayasi, K. Abe, S. Sezai, M. Hirano, and H. Oka. 1994. Anti-ulcer effect of Bifidobacterium bifidum YIT 4007. Jpn. Pharmacol. Ther. 22:4743-4746. (in Japanese)

Yamaoka, Y., M. Kita, T. Kodama, N. Sawai, K. Kashima, and J. Imanishi. 1997. Induction of various cytokines and development of severe mucosal inflammation by cagA gene positive Helicobacter pylori strains. Gut 41:442-451.

Yamaoka, Y., M. Kita, T. Kodama, N. Sawai, T. Tanahashi, K. Kashima, and J. Imanishi. 1998. Chemokines in the gastric mucosa in Helicobacter pylori infection. Gut 42:609-617.

Yildirim, Z., and M. G. Johnson. 1998. Characterization and antimictobial spectrum of Bifidicin B, a bacteriocin produced by Bifidobacterium bifidum NCFB 1454. J. Food Prot. 61:47-51.

Yoshihara, M., K. Sumii, K. Haruma, K. Kiyohira, N. Hattori, Y. Kitadai, K. Komoto, S. Tanaka, and G. Kajiyama. 1998. Correlation of ratio of serum pepsinogen I and II with prevalence of gastric cancer and adenoma in Japanese subjects. Am. J. Gastroenterol. 93:1090-1096. 